\title{
Luigi Luzzatti, "pionero del crédito popular»
}

\author{
Javier Divar Garteiz-Aurrecoa
}

Universidad de Deusto

Sumario: I. Introducción. II. Luzzatti, profesor universitario. III. Luigi Luzzatti, político. IV. Bibliografía.

Resumen: Luigi Luzzatti, profesor y político italiano, es considerado uno de los «padres» del crédito popular, a más de ser también uno de los promotores de las políticas públicas proteccionistas.

Palabras clave: crédito popular.

Abstract: Luigi Luzzati, Italian professor and politician, is considered to be one of the "fathers» of credit unions and also one of the major advocates of public protectionist policy.

Key words: credit unions. 


\section{Introducción}

La figura de Luigi Luzzatti es muy destacable en el ámbito de la historia internacional del Cooperativismo por su contribución ideológica y práctica al crédito popular, esencial para la financiación de la economía social.

Pero además, Luzzatti destaca como político al servicio del Estado, en la defensa de los intereses económicos de Italia, actuando como un auténtico patriota italiano y como benefactor de las clases humildes y trabajadoras.

También fue Luzzatti un prestigioso profesor universitario, impartiendo docencia en Milán y Padua, al tiempo que en este ámbito académico fue muy reconocido por publicar obras de gran influencia económica.

Como economista, partiendo de posiciones liberales inició la política proteccionista en beneficio de una dirección social de la economía pública, recorriendo el camino desde el librecambismo al proteccionismo arancelario, con lo que desde el Ministerio del Tesoro (ocupó por cuatro veces el cargo de ministro del ramo) consolidó la lira italiana en los mercados internacionales.

Nació Luigi Luzzatti en Venecia, el 1 de marzo de 1841, en el seno de una familia judía mercantil (su padre era propietario de una industria textil), que le procuró una esmerada educación y un espíritu abierto y liberal. No es por ello raro que Luzzatti fuera toda su vida un antidogmático, defensor de la tolerancia religiosa y de la libertad de conciencia.

Estudió Derecho en la prestigiosa Universidad de Padua, en la que tuvo como profesor al catedrático de Economía Política Dr. A. Messedaglia, que ejerció una notable influencia sobre Luzzatti, al que consideró como discípulo predilecto y con el que después entabló una gran amistad. La especialidad de Messedaglia en Finanzas Públicas explica bien la línea vital de Luigi Luzzatti.

\section{Luzzatti, profesor universitario}

Tras sus estudios en Padua, Luzzatti obtuvo una plaza como profesor de Economía Política en el Instituto Técnico de Milán, en 1863, año en el que publica su obra más famosa, "La difusión del Crédito y la Banca Popular», en la que seguía las teorías económicas de Franz Hermann Schulze-Delitzsch (1808-1883), pionero del cooperativismo alemán, que como diputado de la Asamblea Nacional participó activamente en el Código Cooperativo del 27 de marzo de 1867, una de las primeras legislaciones cooperativas del mundo. 
Su investigación sobre el crédito popular le condujo a fundar con T. ZaIli, en 1864, la Banca Popular de Lodi, primera banca popular de Italia.

Difundió su ideario sobre el crédito cooperativo como basamento de la economía popular o social mediante numerosos artículos en el diario «ll Sole».

Participó con F. Ferrara en la fundación en Venecia de la Escuela Superior de Comercio «C. Foscari», primer centro de Italia para la enseñanza especializada en Ciencias Económicas.

Su fama le procuró la oferta de su Universidad de Padua, en 1866, para ocupar una plaza como profesor extraordinario de Derecho Constitucional, pero pospuso la aceptación para contribuir a la fundación en Milán (1867) de la Asociación Industrial Italiana.

En ese mismo año de 1867 se incorporó Luzzatti como profesor de la Universidad de Padua, pero su vida académica quedó interrumpida por su nombramiento en 1869 como Subsecretario de Estado de Agricultura y Comercio, cargo desde el que inicia el régimen proteccionista italiano.

El nombramiento le vino a Luzzatti de la mano de su mentor político Marco Minghetti, que había publicado en 1859 un libro de Economía de tendencia social, titulado "Della economía pubblica e delle sue atínense colla morale e col diritto», que influyó en la visión de Luzzatti de la economía pública como instrumento de política social.

Precisamente en ese año de 1869 participó Luzzatti en la creación de una Comisión Consultiva gubernamental, formada por personalidades independientes, para preparar la legislación social italiana sobre cajas de ahorros, cooperativas, entidades de previsión social, sanidad laboral y empleo femenino y de menores ( entre sus logros es destacable la promulgación en Italia en 1886 de la primera ley reguladora del trabajo infantil).

Entre las publicaciones principales de Luigi Luzzatti, a más de la ya destacada "La Difusión del Crédito y la Banca Popular» (1863), podemos destacar "La investigación industrial y los Tratados de Comercio» (1878) y «La libertad de conciencia y ciencia» (1909). También debe destacarse por su lucidez el prefacio a la edición italiana (Monza, 1919) de la obra de V. Totomianz, «La Cooperazione in Russia», editada por la Cooperativa Obrera Litográfica de Monza.

\section{Luigi Luzzatti, político}

Tras su paso por la Subsecretaría de Agricultura y Comercio, Luzzatti continuó con su labor como profesor universitario hasta 
que en 1891 el Primer Ministro Di Rudini, en su primer gobierno, le nombró Ministro del Tesoro, cargo en el que puso en práctica su política proteccionista económica y asentó la lira italiana en los mercados.

Con ello Luigi Luzzatti fue adquiriendo un prestigio como ministro imprescindible en el campo de la Hacienda y las Finanzas públicas, por lo que nuevamente, en el tercer gobierno de Di Rudini, en 1896, volvió Luzzatti a ser designado como Ministro del Tesoro de Italia.

La buena fama y el buen hacer público de Luzzatti le llevó a ser nombrado por tercera vez Ministro del Tesoro, en 1903, en el segundo gobierno de G. Giolitti.

Y todavía por cuarta vez, fue Luzzatti nombrado Ministro del Tesoro en 1906, en el gobierno de Sonnino.

El propio Sonnino, en su segundo gobierno, designó a Luzzatti Ministro de Agricultura, Industria y Comercio, en 1907.

Finalmente, en 1910, Luigi Luzzatti fue nombrado Presidente del Consejo de Ministros de Italia, lo que culminó su espléndida vida política al servicio de la nación.

En 1921 fue nombrado Senador vitalicio, en reconocimiento a sus continuados servicios a Italia.

El 29 de marzo de 1927, murió en Roma el muy ilustre ciudadano italiano Luigi Luzzatti, protector de la nación, protector de los trabajadores y protector de la economía social.

La Doctrina Cooperativa tiene siempre un lugar destacado en su memoria.

\section{Bibliografía}

CAPUzzo, Ester. «Luigi Luzzatti e il sionismo». R.S.S., ob. cit., pp. 693 a 701.

FrANCHETTI NAHOR, Luisa. "Dalla comunità ebraica di Venezia alla guida dell'Italia». Rvta. Studi Storici, ob. cit., pp. 623 y 624.

FRANCHINI, Sandro G. «Le carte di Luigi Luzzatti per la storia d'Italia». R.S.S., ob. cit., pp. 625 a 639.

GhisalberTI, Carlo. «Luigi Luzzatti uomo politico». R.S.S., ob. cit., pp. 641 a 652.

HULLRICHT, Harmut. «Luigi Luzzatti e i liberali tedeschi». En la obra colectiva Luigi Luzzatti e il suo tempo (pp. 57 a 116). Instit. Veneto di Scienze Lettere ed Arti. Venezia, 1994.

LuzzATto, Amos. «Luigi Luzzatti veneziano e ebreo». R.S.S., ob. cit., pp. 653 a 660.

MARUCCO, Dora. "Luigi Luzzatti e gli esordi della legislazione sociale». En Luigi Luzzatti e il suo tempo, ob. cit., pp. 409 a 424. 
MinerbI, Sergio I.. «Luigi Luzzatti, libertad, religión, solidaridad». Rvta. Studi Storici, vol. 43, n. ${ }^{\circ} 4,2007$, pp. 661 a 682.

PeCorarl, Paolo. «Lo storicismo economico di Luigi Luzzatti». En Luigi Luzzatti e il suo tempo, ob. cit., pp. 197 a 213.

—, Ballinı. Pierluigi. "Luzzatti, Luigi». Dizionario Biografico degli Italiani, volume 66 (2007).

ScazzochIo, Umberto. Luigi Luzzatti, hombre de Estado italiano. Congreso Judío Latino Americano. Edic. Stanford Libraires. Buenos Aires, 1975.

ZALIN, Giovanni. "Crescita economica, protezionismo industriale e política dei trattati commerciali in Luigi Luzzatti». En Liugi Luzzatti e il suo tempo, ob. cit., pp. 215 a 258. 